\title{
A Simple Risk Scoring Systems to evaluate the presence of aneurysm and one-year mortality in patients with abdominal aortic aneurysm using CHA2DS2-VASc and ATRIA
}

\author{
Fatih Aksoy* (1), Dinçer Uysal ${ }^{2}$ (1)
}

\section{SUMMARY}

OBJECTIVE: We aimed to demonstrate the clinical utility of $\mathrm{CHA}_{2} \mathrm{DS}_{2}-\mathrm{VASC}$ and anticoagulation and risk factors in atrial fibrillation risk scores in the assessment of one year mortality in patients with abdominal aortic aneurysm.

METHODS: We designed a retrospective cohort study using data from Suleyman Demirel University Hospital for the diagnosis of abdominal aortic aneurysm. The study included 120 patients with abdominal aortic aneurysm who underwent aortic computed tomography. Patients were divided into two groups according to presence of abdominal aortic aneurysm and the development of mortality. Predictors of mortality were determined by multiple logistic regression analysis.

RESULTS: Multivariate regression analysis showed that $\mathrm{CHA}_{2} \mathrm{DS}_{2}$-VASc score, advanced age, female gender and elevated white blood cell counts were independent predictors of abdominal aortic aneurysm development while $\mathrm{CHA}_{2} \mathrm{DS}_{2}$-VASc score and elevated glucose levels were independent predictors of one year mortality in patients with abdominal aortic aneurysm. The concordance statistics for anticoagulation and risk factors in atrial fibrillation risk Score and $\mathrm{CHA}_{2} \mathrm{DS}_{2}-\mathrm{VASC}$ risk score respectively were 0.96 and 0.97 and could significantly predict one year mortality in patients with abdominal aortic aneurysm ( $p<0.001$, and $p<0.001$, respectively).

CONCLUSIONS: $\mathrm{CHA}_{2} \mathrm{DS}_{2}$-VASC and anticoagulation and risk factors in atrial fibrillation risk scores are easily obtained in an emergency setting and can accurately predict one year mortality as a noninvasive follow-up in patients with abdominal aortic aneurysm. These simple scores could be used as a point of care decision aid to help the clinician in counseling patients presenting with abdominal aortic aneurysm and their families on treatment protocols.

KEYWORDS: Aortic aneurysm. Abdominal. Mortality. Risk assessment. Methods.

\section{INTRODUCTION}

Abdominal aortic aneurysm (AAA), which is characterized by abnormal focal dilation of the abdominal aorta, is relatively common and is associated with significant morbidity and mortality. AAA, whose prevalence increases with age, is the most common vascular disease of the abdominal aorta in clinical practice, affecting $3 \%$ of the population aged over 50 years ${ }^{1,2}$. Although most AAA patients are asymptomatic, some patients are admitted to the emergency services for life-threatening symptoms and have an in-hospital mortality of about $40 \%$. Therefore, foreseeing the development of aneurysm and regression could be beneficial for survival. Recent studies have demonstrated a strong association between AAA and cardiovascular risk factors ${ }^{3,4}$.

The $\mathrm{CHA}_{2} \mathrm{DS}_{2}-\mathrm{VASc}$ and Anticoagulation and Risk Factors in Atrial Fibrillation (ATRIA) risk scores are simple and effortless scoring systems that are used to predict the risk of thromboembolism in non-valvular atrial fibrillation (AF) patients ${ }^{5,6}$. Additionally, these scoring systems have been associated with

\footnotetext{
'Suleyman Demirel University, Medical School, Department of Cardiology-Isparta, Turkey

${ }^{2}$ Suleyman Demirel University, Medical School, Department of Cardiovascular surgery-Isparta, Turkey

*Corresponding author: dr.aksoy@hotmail.com

Conflicts of interest: the authors declare there are no conflicts of interest. Funding: none.

Received on August 10, 2020. Accepted on September 02, 2020.
} 
worse clinical outcomes in patients with acute coronary syndrome regardless of the presence of $\mathrm{AF}^{7,8}$.

The aim of the study was to evaluate whether $\mathrm{CHA}_{2} \mathrm{DS}_{2}$ VASc and ATRIA risk scores could accurately predict AAA and 12-month mortality after discharge of AAA patients.

\section{METHODS}

\section{Patients}

In this observational and cross-sectional study, we retrospectively screened data from patients with intact infrarenal AAA who were admitted to either the Emergency Department or the Outpatient Clinics at Suleyman Demirel University Education and Research Hospital between January 2014 and August 2019. Cases were excluded if they had incomplete clinical or para-clinical data, infectious aneurysms, need for preoperative resuscitation, ruptured/symptomatic AAA or previous endovascular treatment. The extracted clinical data included gender, age, size of the aneurysm, presence of hypertension, diabetes, chronic renal failure, heart failure, cerebrovascular event, peripheral vascular disease, hospitalization duration, and in-hospital mortality rate. The aneurysm size was measured on preoperative computed tomography angiograms. The study was approved by the medical ethical committee of Suleyman Demirel University's School of Medicine and all patients signed a written informed consent (Decision $\mathrm{N}^{\circ}$ 13.12.2018-247). A total of 178 patients were screened and 58 subjects were excluded after applying the exclusion criteria. The final study group consisted of 120 patients who met the inclusion and exclusion criteria. Patients were divided into two groups according to the presence of AAA.

\section{Statistical analysis}

All calculations were performed using the Statistical Package for Social Sciences software, SPSS 16.0 (SPSS Inc, Chicago, Illinois). Continuous variables were expressed as mean (standard deviation) or median (interval between quartiles); categorical variables were expressed as frequency (\%) and numbers. Kolmogorov-Smirnov test was used in the evaluation of normality. Continuous variables were compared using the Mann-Whitney U test or the Student's $t$-test, whereas categorical variables were compared using the $\chi^{2}$ test or the Fisher test. In all statistical analyses, $\mathrm{p}<0.05$ was considered as statistically significant. The correlations were analyzed through Pearson or Spearman correlation analyses where appropriate. To investigate the association between the variables, AAA, and one year mortality, univariate regression analysis was performed, and variables with $\mathrm{p}<0.10$ were performed in the multivariate logistic regression analysis. Receiver operating characteristics (ROC) curve analysis was performed to analyze the prognostic value of ATRIA and $\mathrm{CHA}_{2} \mathrm{DS}_{2}-\mathrm{VASc}$ risk scores for detecting AAA and one-year mortality. C-Statistic (area under the curve) was presented as a unified estimate of sensitivity and specificity.

\section{Clinical outcomes and definitions}

One year after discharge, the patients were investigated for the cause of death (cardiac or non-cardiac) via telephone calls. Computer assisted tomography was used to visualize the aorta and to determine the maximal aneurysm diameter. A diameter of $35 \mathrm{~mm}$ or more at the level of the infrarenal abdominal aorta was defined as an abdominal aortic aneurysm. The $\mathrm{CHA}_{2} \mathrm{DS}_{2}$-VASc and ATRIA scores were calculated as stated in previous studies ${ }^{5,6}$.

\section{RESULTS}

A total of 120 patients (mean age: $64 \pm 12$ years; range, 35-95 years) were included in this study. During the follow-up period, 25 patients $(20.8 \%)$ died. The demographic and clinical characteristics of patients with and without aneurysm are listed in Table 1. The demographic and clinical characteristics of aneurysm patients with and without mortality are listed in Table 1. Patients with aneurysm had significantly higher mean $\mathrm{CHA}_{2} \mathrm{DS}_{2}$-VASc $(2.6 \pm 1.9$ versus $1.4 \pm 1.3, \mathrm{p}<0.001)$ and ATRIA scores $(5.0 \pm 3.7$ versus $4.3 \pm 2.7$ versus, $\mathrm{p}<0.001)$ compared to patients without aneurysm. The mean $\mathrm{CHA}_{2} \mathrm{DS}_{2}$-VASc and ATRIA scores were significantly higher in patients with mortality compared to patients without mortality $(4.9 \pm 1.2$ versus $1.4 \pm 0.9, \mathrm{p}<0.001 ; 9.2 \pm 2.2$ versus $2.9 \pm 2.2, \mathrm{p}<0.001$; respectively). A multivariate binary logistic regression analysis was carried out by including all characteristics associated with the development of AAA in the univariate analysis (Table 2). This analysis showed that $\mathrm{CHA}_{2} \mathrm{DS}_{2}-\mathrm{VASc}$ score $(\mathrm{OR}=1.39$; 95\%CI 1.08-1.80, $\mathrm{p}=0.01)$, female gender $(\mathrm{OR}=2.92 ; 95 \% \mathrm{CI}$ 1.25-6.82, $\mathrm{p}=0.01)$, and white blood cell count $(\mathrm{OR}=1.11$; 95\% CI 1.03-1.20, $\mathrm{p}=0.006)$ remained as independent risk factors for AAA development. ROC curve analysis showed that both ATRIA score (C-statistic: 0.68; 95\%CI 0.59-0.78, $\mathrm{p}<0.001)$ and $\mathrm{CHA}_{2} \mathrm{DS}_{2}$-VASc score (C-statistic: $0.67 ; 95 \% \mathrm{CI}$ $0.58-0.77, p=0.001)$ were significant predictors of AAA. We calculated that a cut-off point of 3.5 for ATRIA and 1.5 for $\mathrm{CHA}_{2} \mathrm{DS}_{2}$-VASc scores could estimate the development of AAA with a sensitivity of 58 and $70 \%$ and a specificity of 66 and $65 \%$, respectively. A pair-wise comparison of ROC curves indicated that the predictive value of the ATRIA risk score and $\mathrm{CHA}_{2} \mathrm{DS}_{2}$-VASc score were similar for the prediction of AAA development (AUC ATRIA versus AUC CHA $\mathrm{DS}_{2}$-VASc, z test $=0.561, \mathrm{p}=0.574$; DeLong method). A multivariate binary 
logistic regression analysis was carried out by including all characteristics that were associated with mortality in patients with AAA in the univariate analysis (Table 2). This analysis showed that a high $\mathrm{CHA}_{2} \mathrm{DS}_{2}$-VASc score $(\mathrm{OR}=29.04 ; 95 \% \mathrm{CI}$ 2.34-359.09, $\mathrm{p}=0.009)$ and glucose level $(\mathrm{OR}=1.02$; 95\%CI $1.00-1.05, p=0.05$ ) remained as independent risk factors for mortality in patients with AAA (Table 2). ROC curve analysis showed that both ATRIA score (C-statistic: 0.96; 95\%CI 0.91-1.00, $\mathrm{p}<0.001)$ and $\mathrm{CHA}_{2} \mathrm{DS}_{2}$-VASc score (C-statistic: 0.97 ; $95 \%$ CI $0.93-1.00, \mathrm{p}<0.001)$ were significant predictors of mortality in patients with AAA (Figure 1). A cut-off score of 6 for ATRIA and 3 for $\mathrm{CHA}_{2} \mathrm{DS}_{2}$-VASc were calculate to be able to estimate mortality in patients with AAA with a sensitivity of 85 and $92 \%$ and a specificity of 85 and $100 \%$, respectively. A pair-wise comparison of ROC curves was performed and estimated that the predictive value of the ATRIA and $\mathrm{CHA}_{2} \mathrm{DS}_{2}$-VASc risk scores were similar in the prediction of mortality in patients with AAA (AUC ATRIA versus AUC $\mathrm{CHA}_{2} \mathrm{DS}_{2}$-VASc, $\mathrm{z}$ test $=0.974, \mathrm{p}=0.33$, DeLong method).

\section{DISCUSSION}

The present study identified a significant relationship between $\mathrm{CHA}_{2} \mathrm{DS}_{2}$-VASc and ATRIA risk sores and the development of AAA. Moreover, the present study demonstrated that $\mathrm{CHA}_{2} \mathrm{DS}_{2}$ VASc and ATRIA risk sores could strongly predict one-year mortality in patients with AAA. Our data suggest that these scores might be used as prognostic predictors in patients with AAA.

It has been previously reported that the presence of structural diseases such as mitral annular calcification and an increase in epicardial adipose tissue were associated with high $\mathrm{CHA}_{2} \mathrm{DS}_{2}-$ VASc scores ${ }^{9,10}$. Additionally, the same studies also showed that echocardiographic left ventricular measurements were associated with high $\mathrm{CHA}_{2} \mathrm{DS}_{2}-\mathrm{VASc}$ scores. Corroborating these data, AAA, a structural disease, was shown to be associated with a high $\mathrm{CHA}_{2} \mathrm{DS}_{2}-\mathrm{VASc}$ score. The $\mathrm{CHA}_{2} \mathrm{DS}_{2}$-VASc score was previously reported to be associated with in-hospital and long-term adverse clinical outcomes, including mortality, in patients with both stable coronary artery disease and acute coronary syndrome ${ }^{11,12}$. Similarly, the present study showed

Table 1. Demographic and clinical characteristics of patients with and without AAA; AAA patients with and without mortality

\begin{tabular}{|c|c|c|c|c|c|c|}
\hline & $\begin{array}{c}\text { Aneurysm }(-) \\
\quad(n=60)\end{array}$ & $\begin{array}{l}\text { Aneurysm }(+) \\
(n=60)\end{array}$ & $\mathrm{p}$-value & $\begin{array}{l}\text { Mortality (-) } \\
(n=40)\end{array}$ & $\begin{array}{l}\text { Mortality (+) } \\
(n=20)\end{array}$ & $p$-value \\
\hline CHA2DS2-VASc score & $1.4 \pm 1.3$ & $2.6 \pm 1.9$ & $<0.001$ & $1.4 \pm 0.9$ & $4.9 \pm 1.2$ & $<0.001$ \\
\hline ATRIA score & $2.7 \pm 2.7$ & $5.0 \pm 3.7$ & $<0.001$ & $2.9 \pm 2.2$ & $9.2 \pm 2.2$ & $<0.001$ \\
\hline Age, years & $60.7 \pm 11.0$ & $67.7 \pm 13.2$ & $<0.001$ & $62.5 \pm 12.4$ & $78.2 \pm 7.5$ & $<0.001$ \\
\hline Female gender $n, \%$ & $15(25)$ & $30(50)$ & 0.004 & $18(45)$ & $12(60)$ & 0.224 \\
\hline Hypertension n, \% & $41(68.3)$ & $49(81.7)$ & 0.07 & $29(75)$ & $20(100)$ & 0.007 \\
\hline Diabetes mellitus n, \% & $11(18.3)$ & $19(31.7)$ & 0.07 & $5(12.5)$ & $14(70)$ & $<0.001$ \\
\hline Stroke-TIA n, \% & $5(8.3)$ & $17(28.3)$ & 0.004 & $1(2.5)$ & $16(80)$ & $<0.001$ \\
\hline Mortality n, \% & $5(8.3)$ & $20(33.3)$ & 0.001 & & & \\
\hline Hemoglobin (mg/dL) & $13.4(2.4)$ & $12.1(2.3)$ & 0.004 & $12.6 \pm 2.2$ & $11.0 \pm 2.3$ & 0.01 \\
\hline White blood cell & $8743 \pm 4100$ & $12258 \pm 3500$ & 0.001 & $11.9 \pm 6.8$ & $12.8 \pm 5.9$ & 0.643 \\
\hline Platelet & $222474 \pm 12580$ & $236236 \pm 11700$ & 0.484 & $245 \pm 108$ & $257 \pm 131$ & 0.710 \\
\hline Glucose (mg/dL) & $121 \pm 45.6$ & $122 \pm 45.6$ & 0.959 & $106 \pm 33.1$ & $153 \pm 51.6$ & $<0.001$ \\
\hline Creatinin (mg/dL) & $1.2 \pm 1.0$ & $1.2 \pm 0.7$ & 0.979 & $1.0 \pm 0.3$ & $1.5 \pm 1.1$ & 0.03 \\
\hline Total cholesterol (mg/dL) & $200.2 \pm 41.2$ & $190.9 \pm 38.1$ & 0.310 & $195.4 \pm 35.2$ & $193.2 \pm 32.1$ & 0.560 \\
\hline HDL cholesterol (mg/dL) & $40 \pm 8.0$ & $41 \pm 7.5$ & 0.790 & $39.0 \pm 9.1$ & $40 \pm 7.5$ & 0.760 \\
\hline LDL cholesterol (mg/dL) & $125 \pm 29$ & $127 \pm 35$ & 0.915 & $107 \pm 47$ & $92 \pm 43$ & 0.245 \\
\hline Triglycerides (mg/dL) & $156 \pm 95$ & $136 \pm 32$ & 0.105 & $154.0 \pm 65$ & $140.1 \pm 52$ & 0.260 \\
\hline LV ejection fraction (\%) & $60.1 \pm 0,3$ & $60.2 \pm 0,3$ & 0.962 & $60.2 \pm 0,3$ & $60.7 \pm 0,3$ & 0.480 \\
\hline Aneurysm diameter ( $\mathrm{mm})$ & $20.72 \pm 1.3$ & $53.63 \pm 7.2$ & $<0.001$ & $53.8 \pm 7.5$ & $53.2 \pm 6.8$ & 0.776 \\
\hline
\end{tabular}

Data presented as mean \pm standart deviation or number (\%) of the patients; CHA2DS2-VASc: congestive heart failure, hypertension, age $\geq 75$ years, diabetes mellitus, previous stroke, vascular disease, age 65 to 74 years, female gender; ATRIA: Anticoagulation and risk factors in atrial fibrillation risk score; TIA: Transient ischemic attack; LV: Left ventricular. 
that high scores may also be related to one-year mortality. Moreover, these scores were associated with contrast-induced nephropathy and poor coronary perfusion after primary percutaneous coronary intervention ${ }^{13,14}$. The $\mathrm{CHA}_{2} \mathrm{DS}_{2}$-VASc score, which was created from $\mathrm{CHADS}_{2}$, is recommended in contemporary guidelines for appraising oral anticoagulant therapy in patients with non-valvular $\mathrm{AF}^{6}$. Although the underlying mechanisms of AAA are not fully understood, previous studies have shown that systemic processes often caused alterations in the vascular wall, leading to a loss of vascular structural proteins and wall strength. Older age, male gender, cigarette smoking, Caucasian race, atherosclerosis, hypertension, family history of AAA, and other large artery aneurysms are the most important risk factors for the development of $A_{A A}{ }^{15}$. The $\mathrm{CHA}_{2} \mathrm{DS}_{2}$-VASc and ATRIA scores evaluate similar risk factors for AAA; suggesting that these scores can be used to predict the risk of $\mathrm{AAA}^{16}$. To the best of our knowledge, no published study has investigated the relationship between AAA and the CHA2DS2-VASc score.

Although most AAA patients are asymptomatic, rupture is a mortal complication of AAA and has an in-hospital mortality rate of about $50 \%$. Even if patients are operated on, surgery-related mortality has been reported to be up to $70 \%^{15,17}$. However, the elective surgery mortality rates were reported to be lower than emergent surgery mortality rates ${ }^{17,18}$. Reliable prediction of outcomes in patients with AAA and efficient follow-up are very important to reduce mortality and decrease healthcare costs. Edinburgh Ruptured Aneurysm Score (ERAS), Hardman Index (HI), and Glasgow Aneurysm Score (GAS) are the three risk evaluation scores that have been established to predict the development of AAA ${ }^{19,20}$. However, Gatt et al. ${ }^{21}$ showed that HI and GAS were weak predictors of outcome after rupture of AAA

Table 2. Predictors of AAA and mortality in univariate and multivariate regression analysis

\begin{tabular}{|c|c|c|c|c|c|c|c|c|c|c|c|c|}
\hline & \multicolumn{3}{|c|}{$\begin{array}{l}\text { Univariate analysis for } \\
\text { AAA presence }\end{array}$} & \multicolumn{3}{|c|}{$\begin{array}{l}\text { Multivariate analysis } \\
\text { for AAA presence }\end{array}$} & \multicolumn{3}{|c|}{$\begin{array}{l}\text { Univariate analysis } \\
\text { for mortality }\end{array}$} & \multicolumn{3}{|c|}{$\begin{array}{l}\text { Multivariate analysis } \\
\text { for mortality }\end{array}$} \\
\hline & OR & $95 \% \mathrm{Cl}$ & $p$-value & OR & $95 \% \mathrm{Cl}$ & $\mathrm{p}$-value & OR & $95 \% \mathrm{Cl}$ & p-value & OR & $95 \% \mathrm{Cl}$ & p-value \\
\hline $\begin{array}{l}\text { ATRIA risk } \\
\text { score }\end{array}$ & 1,237 & $\begin{array}{c}(1.097- \\
1.394)\end{array}$ & 0.001 & & & & 2.49 & $\begin{array}{r}(1.56- \\
3.97)\end{array}$ & $<0.001$ & & & \\
\hline $\begin{array}{l}\text { CHA2DS2VASC } \\
\text { risk score }\end{array}$ & 1.516 & $\begin{aligned}(1.190- \\
1.932)\end{aligned}$ & 0.001 & 1.39 & $\begin{array}{l}(1.08- \\
1.807)\end{array}$ & 0.01 & 15.13 & $\begin{array}{l}(2.34- \\
97.59)\end{array}$ & 0.004 & 29.04 & $\begin{array}{l}(2.34- \\
359.09)\end{array}$ & 0.009 \\
\hline Age & 1.048 & $\begin{array}{c}(1.016- \\
1.081)\end{array}$ & 0.003 & & & & 1.14 & $\begin{array}{r}(1.06- \\
1.22)\end{array}$ & $<0.001$ & & & \\
\hline Female gender & 3.00 & $\begin{array}{c}(1.38- \\
6.4) \\
\end{array}$ & 0.005 & 2.92 & $\begin{array}{c}(1.25- \\
6.82)\end{array}$ & 0.01 & & & & & & \\
\hline Hypertension & 2.06 & $\begin{array}{c}(0.88- \\
4.83)\end{array}$ & 0.095 & & & & & & & & & \\
\hline $\begin{array}{l}\text { Diabetes } \\
\text { Mellitus }\end{array}$ & 2.06 & $\begin{array}{c}(0.88- \\
4.83)\end{array}$ & 0.095 & & & & & 16.33 & $\begin{array}{l}(4.28- \\
62.31)\end{array}$ & $<0.001$ & & \\
\hline Stroke/TIA & 4.34 & $\begin{array}{c}(1.48- \\
12.7)\end{array}$ & 0.007 & & & & & & & & & \\
\hline Hemoglobin & 0.80 & $\begin{array}{c}(0.68- \\
0.93)\end{array}$ & 0.005 & & & & & 0.71 & $\begin{array}{r}(0.55- \\
0.93)\end{array}$ & 0.014 & & \\
\hline $\begin{array}{l}\text { White blood } \\
\text { cell }\end{array}$ & 1.13 & $\begin{array}{c}(0.04- \\
1.22)\end{array}$ & 0.002 & 1.11 & $\begin{array}{c}(1.03- \\
1.20)\end{array}$ & 0.006 & & & & & & \\
\hline Glucose & & & & & & & 1.03 & $\begin{array}{c}(1.01- \\
1.05) \\
\end{array}$ & 0.002 & 1.02 & $\begin{array}{r}(1.00- \\
1.05) \\
\end{array}$ & 0.05 \\
\hline GFR & & & & & & & 0.97 & $\begin{aligned}(0.94- \\
0.99)\end{aligned}$ & 0.03 & & & \\
\hline Creatinine & & & & & & & 2.41 & $\begin{array}{l}(0.90- \\
6.43)\end{array}$ & 0.07 & & & \\
\hline
\end{tabular}

OR: odds ratio; Cl: confidence interval; CHA2DS2-VASc: congestive heart failure, hypertension, age $\geq 75$ years, diabetes mellitus, previous stroke, vascular disease, age 65 to 74 years, female gender; ATRIA: anticoagulation and risk factors in atrial fibrillation risk score; TIA: transient ischemic attack; GFR: glomerular filtration rate. 
repair and no thorough validation of ERAS has been performed in an independent cohort. A variety of scores have been evaluated in previous studies for predicting mortality risk in patients with ruptured $\mathrm{AAA}^{22-24}$. Healey et al. ${ }^{22}$ showed that advanced age, elevated creatinine and low systolic blood pressure were associated with 30-day mortality in patients with ruptured AAA who were being considered for repair in the endovascular area. Wise et al. ${ }^{23}$ determined that the GAS score could predict mortality in patients with ruptured AAA. Vos et al. ${ }^{24}$ evaluated the presence of a relationship between the mortality risk in patients with ruptured AAA and five different aneurysm scoring systems, including GAS, HI, the Vancouver Scoring System (VSS), ERAS, and Dutch Aneurysm Score. These authors reported a statistically significant difference only between the VSS and the GAS scores in favor of the VSS. Unlike these studies, the current study

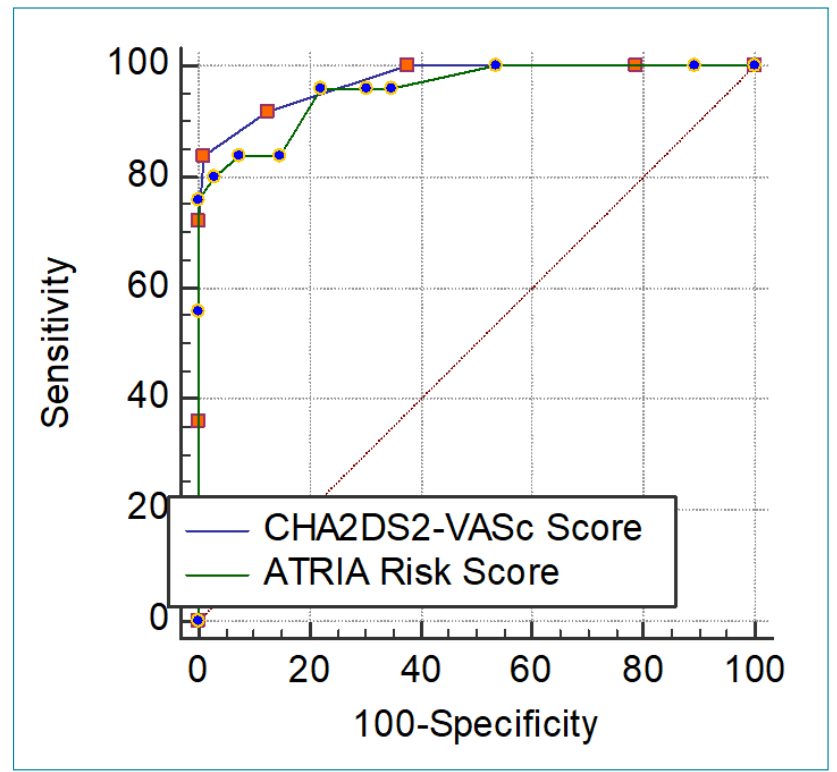

Figure 1. Receiver operating characteristic (ROC) curve with calculated area under the curve and optimal cut-off point for the $\mathrm{CHA}_{2} \mathrm{DS}_{2}$ VASC score and anticoagulation and risk factors in atrial fibrillation risk score to identify the presence of one year mortality in patients with abdominal aortic aneurysm. reports that $\mathrm{CHA}_{2} \mathrm{DS}_{2}$-VASc and ATRIA risk scores, two simple risk models for predicting thromboembolic risk in patients with non-valvular AF, were associated with developmental aneurysm and could predict one-year mortality in patients with un-ruptured AAA. Other aneurysm scoring systems are complex and time-consuming as they also require clinical and laboratory variables that may not be available to the clinician immediately. The present study showed that, in addition to predicting the development of AAA, the $\mathrm{CHA}_{2} \mathrm{DS}_{2}$-VASc and ATRIA scores were positively correlated with the size of the aneurysm and, subsequently, with the risk of rupture. Additionally, patients with high $\mathrm{CHA}_{2} \mathrm{DS}_{2}-$ VASc and ATRIA scores showed an increased risk of mortality. Therefore, patients with high ATRIA and $\mathrm{CHA}_{2} \mathrm{DS}_{2}$-VASc risk scores should be screened with ultrasonography or, if indicated, angiography. Risk modifications should be administrated to decrease morbidity and mortality.

In conclusion, supporting our hypothesis, the current study shows that the $\mathrm{CHA}_{2} \mathrm{DS}_{2}-\mathrm{VASc}$ and ATRIA risk scores were strong independent predictors of one year mortality in patients with AAA and may identify patients who will benefit most from early invasive management. Individuals with high $\mathrm{CHA}_{2} \mathrm{DS}_{2}-\mathrm{VASc}$ and ATRIA risk scores should be advised to pay more attention to the reduction of unfavorable cardiovascular risk factors and the development of future cardiovascular events. Additionally, lifestyle changes and cardiovascular risk modifications may reduce cardiac and vascular structural changes such as left atrial dilatation, left ventricular hypertrophy, and aortic dilatation. Moreover, individuals with high $\mathrm{CHA}_{2} \mathrm{DS}_{2}-\mathrm{VASc}$ and ATRIA risk scores should undergo open or endovascular treatment to decrease the risk of rupture or should be closely monitored with frequent ultrasonography or angiography to mitigate the risk of rupture.

\section{AUTHORS" CONTRIBUTION}

FA: Conceptualization, Methodology, Project Administration, Writing-Review \& Editing. DU: Resources, Validation, Investigation, Writing-Original Draft.

\section{REFERENCES}

1. LeFevre ML; U.S. Preventive Services Task Force. Screening for abdominal aortic aneurysm: U.S. Preventive Services Task Force recommendation statement. Ann Intern Med. 2014;161(4):281-90. https://doi.org/10.7326/M14-1204

2. Golledge J, Muller J, Daugherty A, Norman P. Abdominal aortic aneurysm: pathogenesis and implications for management. Arterioscler Thromb Vasc Biol. 2006;26(12):2605-13. https://doi.org/10.1161/01. ATV.0000245819.32762.cb
3. Stackelberg O, Wolk A, Eliasson K, Hellberg A, Bersztel A, Larsson SC, et al. Lifestyle and risk of screening-detected abdominal aortic aneurysm in men. J Am Heart Assoc. 2017;6(5):e004725. https://doi.org/10.1161/JAHA.116.004725

4. Sweeting MJ, Thompson SG, Brown LC, Powell JT, RESCAN collaborators. Meta-analysis of individual patient data to examine factors affecting growth and rupture of small abdominal aortic aneurysms. Br J Surg. 2012;99(5):655-65. https://doi.org/10.1002/bjs.8707 
5. Singer DE, Chang Y, Borowsky LH, Fang MC, Pomernacki NK, Udaltsova N, et al. A new risk scheme to predict ischemic stroke and other thromboembolism in atrial fibrillation: the ATRIA study stroke risk score. J Am Heart Assoc. 2013;2(3):e000250. https://doi.org/10.1161/JAHA.113.000250

6. Kirchhof P, Benussi S, Kotecha D, Ahlsson A, Atar D, Casadei $B$, et al. 2016 ESC Guidelines for the management of atrial fibrillation developed in collaboration with EACTS. Eur Heart J. 2016;37(38): 2893-962 . https://doi.org/10.1093/ eurheartj/ehw210

7. Çetinkal G, Koçaş C, Koçaş BB, Arslan Ş, Abacı O, Karaca OŞ, et al. Comparative performance of AnTicoagulation and Risk factors In Atrial fibrillation and Global Registry of Acute Coronary Events risk scores in predicting long-term adverse events in patients with acute myocardial infarction. Anatol J Cardiol. 2018;20(2):77-84. https://doi.org/10.14744/ AnatolJCardiol.2018.54815

8. Kurtul A, Yarlioglues M, Duran M. Predictive value of CHA2DS2-VASC score for contrast-induced nephropathy after percutaneous coronary intervention for acute coronary syndrome. Am J Cardiol. 2017;119(6):819-25. https:// doi.org/10.1016/j.amjcard.2016.11.033

9. Aksoy F, Guler S, Kahraman F, Oskay T, Varol E. The relation between echocardiographic epicardial fat thickness and cha2ds2-vasc score in patients with sinus rhythm. Braz J Cardiovasc Surg. 2019;34(1):41-7. https:// doi.org/10.21470/1678-9741-2018-0230

10. Aksoy F, Guler S, Kahraman F, Kuyumcu MS, Bagcı A, Bas HA, et al. The relationship between mitral annular calcification, metabolic syndrome and thromboembolic risk. Braz J Cardiovasc Surg. 2019;34(5):535-41. https://doi.org/10.21470/16789741-2019-0062

11. Taşolar H, Çetin M, Ballı M, Bayramoğlu A, Otlu YÖ, Türkmen $\mathrm{S}$, et al. CHA2DS2-VASc-HS score in non-ST elevation acute coronary syndrome patients: assessment of coronary artery disease severity and complexity and comparison to other scoring systems in the prediction of in-hospital major adverse cardiovascular events. Anatol J Cardiol. 2016;16(10):742-8. https://doi.org/10.14744/AnatolJCardiol.2015.6593

12. Capodanno D, Rossini R, Musumeci G, Lettieri C, Senni M, Valsecchi O, et al. Predictive accuracy of CHA2DS2-VASc and HAS-BLED scores in patients without atrial fibrillation undergoing percutaneous coronary intervention and discharged on dual antiplatelet therapy. Int J Cardiol. 2015;199:319-25. https:// doi.org/10.1016/j.jicard.2015.07.064

13. Aksoy F, Işik İB, Baş HA, BağCl A, Kahraman F, Okudan YE, et al. Usefulness of the CHA2DS2-VASc score to predict "ST-segment resolution failure" in patients treated with primary percutaneous coronary intervention for ST-segment elevation myocardial infarction. Dicle Univ Tip Fakul Derg. 2019;46(4):847-55. https://doi.org/10.5798/dicletip.570650
14. Aksoy F, Bagcı A. Predictive value of ATRIA risk score for contrast-induced nephropathy after percutaneous coronary intervention for ST-segment elevation myocardial infarction. Rev Assoc Med Bras (1992). 2019;65(11):1384-90. https:// doi.org/10.1590/1806-9282.65.11.1384

15. Kniemeyer HW, Kessler T, Reber PU, Ris HB, Hakki H, Widmer MK. Treatment of ruptured abdominal aortic aneurysm, a permanent challenge or a waste of resources? Prediction of outcome using a multi-organ-dysfunction score. Eur J Vasc Endovasc Surg. 2000;19(2):190-6. https://doi.org/10.1053/ ejvs. 1999.0980

16. Kent KC, Zwolak RM, Egorova NN, Riles TS, Manganaro A, Moskowitz AJ, et al. Analysis of risk factors for abdominal aortic aneurysm in a cohort of more than 3 million individuals. J Vasc Surg. 2010;52(3):539-48. https://doi.org/10.1016/j. jvs.2010.05.090

17. Norman PE, Jamrozik K, Lawrence-Brown MM, Le MT, Spencer CA, Tuohy RJ, et al. Population based randomised controlled trial on impact of screening on mortality from abdominal aortic aneurysm. BMJ. 2004;329(7477):1259. https://doi. org/10.1136/bmj.38272.478438.55

18. Sakalihasan N, Limet R, Defawe OD. Abdominal aortic aneurysm. Lancet. 2005;365(9470):1577-89. https://doi.org/10.1016/ S0140-6736(05)66459-8

19. Tambyraja AL, Lee AJ, Murie JA, Chalmers RT. Prognostic scoring in ruptured abdominal aortic aneurysm: a prospective evaluation. J Vasc Surg. 2008;47(2):282-6. https://doi.org/10.1016/j. jvs.2007.10.031

20. Hardman DT, Fisher CM, Patel MI, Neale M, Chambers J, Lane $\mathrm{R}$, et al. Ruptured abdominal aortic aneurysms: who should be offered surgery? J Vasc Surg. 1996;23(1):123-9. https:// doi.org/10.1016/s0741-5214(05)80042-4

21. Gatt M, Goldsmith P, Martinez M, Barandiaran J, Grover K, El-Barghouti N, et al. Do scoring systems help in predicting survival following ruptured abdominal aortic aneurysm surgery? Ann R Coll Surg Engl. 2009;91(2):123-7. https:// doi.org/10.1308/003588409X359376

22. Healey CT, Neilson M, Clark D, Schanzer A, Robinson W; Vascular Study Group of New England None. Predicting mortality of ruptured abdominal aortic aneurysms in the era of endovascular repair. Ann Vasc Surg. 2017;38:59-63. https:// doi.org/10.1016/j.avsg.2016.09.006

23. Wise ES, Hocking KM, Brophy CM. Prediction of in-hospital mortality after ruptured abdominal aortic aneurysm repair using an artificial neural network. J Vasc Surg. 2015;62(1):815. https://doi.org/10.1016/j.jvs.2015.02.038

24. Vos CG, de Vries JP, Werson DA, van Dongen EP, Schreve $M A$, Ünlü Ç. Evaluation of five different aneurysm scoring systems to predict mortality in ruptured abdominal aortic aneurysm patients. J Vasc Surg. 2016;64(6):1609-16. https:// doi.org/10.1016/j.jvs.2016.05.099 